\title{
Suppression of EGF-R signaling reduces the incidence of prostate cancer metastasis in nude mice
}

\author{
Adriano Angelucci ${ }^{1}$, Giovanni Luca Gravina ${ }^{1}$, Nadia Rucci $^{2}$, Danilo Millimaggi $^{2}$, \\ Claudio Festuccia ${ }^{2}$, Paola Muzi ${ }^{2}$, Anna Teti ${ }^{2}$, Carlo Vicentini ${ }^{1}$ \\ and Mauro Bologna ${ }^{3}$
}

Departments of ${ }^{1}$ Surgery, ${ }^{2}$ Experimental Medicine and ${ }^{3}$ Basic and Applied Biology, University of L'Aquila via Vetoio, Coppito 2 , 67100 L'Aquila, Italy

(Requests for offprints should be addressed to A Angelucci; Email: adriano.angelucci@gmail.com)

\begin{abstract}
The activation of epidermal growth factor receptor (EGF-R) plays a key role in the promotion of proliferation and invasion in prostatic carcinoma (PCa). Gefitinib (Iressa; ZD1839), an orally active EGF-R tyrosine kinase inhibitor, has shown an important anti-proliferative activity in tumors expressing EGF-R both in vitro and in vivo. Our aim was to elucidate the role of gefitinib in the modulation of the metastatic spread of PCa cells. The therapeutic role of gefitinib was investigated by evaluating the proliferative and invasive ability of the PCa cell line PC3 and of its high metastatic sub-line, $\mathrm{PCb} 2$, by in vitro assays and intracardiac injection in nude mice. The inhibitory effect of gefitinib was tested in vivo by injecting PCa cells subcutaneously or in the left ventricle of nude mice and by administrating daily $150 \mathrm{mg} / \mathrm{kg}$ of gefitinib. While xenograft growth was equally reduced in all $\mathrm{PCa}$ lines (about 50\%), the bone metastasis formation was inhibited especially for the high metastatic PCb2 sub-line (81\%) in comparison to PC3 cells (47\%). The comparative in vitro analysis among PCa cell lines showed that PCb2 cells were more sensitive to the inhibitory effect of gefitinib in their invasive ability compared to parental PC3 cells but not in their proliferation rate. Moreover, $\mathrm{PCb} 2$ cells demonstrated an increased invasive ability in vitro in response to bone stromal cell conditioned medium (BCM). The simultaneous presence of $0.1 \mathrm{ng} / \mathrm{ml}$ gefitinib was sufficient to reduce the number of invaded cells in the presence of both EGF and BCM. The molecular characterization of the highly aggressive $\mathrm{PCa}$ sub-lines demonstrated that this phenomenon was associated with an increment in UPA/UPAR axis but not in EGF-R expression. In conclusion, our data suggest that the use of gefitinib as a therapeutic agent may be indicated in the control of $\mathrm{PCa}$ spreading to bone.
\end{abstract}

Endocrine-Related Cancer (2006) 13 197-210

\section{Introduction}

EGF-R is a $170 \mathrm{kDa}$ type I transmembrane glycoprotein containing a ligand-binding ectodomain, a single hydrophobic transmembrane region, and a cytoplasmic tail which includes a tyrosine kinase domain and docking sites for a variety of signaling effectors (Jorissen et al. 2003). The downstream signaling network generated by EGF-R activation is able to control cell growth (Zyzak et al. 1994), survival (Moro et al. 1998) and migration (Frey et al. 2004). Early studies on the of EGF-R in breast and prostate tumor cells have indicated a significant association between EGF-R activation and the acquisition of the invasive phenotype (Zolfaghari \& Djakiew 1996, Kondapaka et al. 1997). In recent years, an increasing number of studies performed with several experimental models have reinforced this hypothesis suggesting a leading role of EGF-R during migration induced by bombesin (Madarame et al. 2003), invasion modulated by urokinase plasminogen activator-receptor (uPA-R) (Mamoune et al. 2004) and bone metastatization (Kim et al. 2003). 
The expression level of uPA-R on disseminated tumor cells was significantly correlated with increasing tumor cell counts in bone marrow and clinical prognosis (Heiss et al. 1995). In particular urokinase plasminogen activator and uPA-R may contribute to the development of an active crosstalk between tumor cells and host cells. This aspect has suggested the hypothesis of a vicious circle, according to which the establishment and growth of metastatic $\mathrm{PCa}$ in bone is determined by an overlapping cellular loop between tumor cells and bone cells (Guise \& Mundy 1998). uPA-R is the best known modulator of UPA activation and it is expressed both by invasive PCa cells and normal osteoblasts (Rabbani et al. 1994). The basic importance of the uPA/uPA-R system in the determination of PCa bone metastases has been clearly demonstrated in experimental animal models by the use UPA and uPA-R inhibitors (Rabbani et al. 1995, Margheri et al. 2005). Recently, some authors have suggested an important correlation between the function of the uPA/uPA-R system and EGF-R activation. For example, EGF-R inhibitors are able to block the signal transduction generated by uPA (Jo et al. 2003), and EGF-R activation is required for important cellular responses stimulated by uPA, such as invasive behavior (Guerrero et al. 2004).

Prostate carcinoma ( $\mathrm{PCa}$ ) develops as a hormonedependent disease. When surgical eradication of the tumor fails, because of the presence of disseminated micrometastases, androgen ablation therapy becomes the treatment of choice. However, the androgen blockade therapy is followed in the majority of patients by the development of a hormone refractory disease, dramatically lowering the median survival expectancy (Small \& Vogelzang 1997). The molecular mechanisms underlying this phenomenon are scarcely known. However, experimental evidence has been provided emphasizing the role of mitogenic signaling pathways other than the androgen receptor axis (Shi et al. 2001). In particular, a significant correlation between the grade of $\mathrm{PCa}$ progression and the expression of EGF-R has been demonstrated (Di Lorenzo et al. 2002). In addition, IHC and microarray analyses have recently indicated that EGF-R is frequently overexpressed in hormone refractory and metastatic PCa (Hernes et al. 2004, Zellweger et al. 2005).

Geftinib (Iressa; ZD1839), a tyrosine kinase inhibitor specific for EGF-R, has been approved as a single drug therapy for lung cancer following very encouraging data obtained in clinical trials (Cohen et al. 2004). To date, a substantial body of information is available in different cancer cells and xenografts describing the inhibition of cell growth by gefitinib
(Wakeling et al. 2002). We have previously shown that the use of gefitinib is effective in inhibiting EGFdependent growth in PCa primary cultures and cell lines, independently of their sensitivity to androgen (Vicentini et al. 2003). Moreover, we and other authors have demonstrated a co-operative effect of antiandrogens and gefitinib, both in vitro (Festuccia et al. 2005b) and in vivo (Sirotnak et al. 2002). A molecular interaction between AR and EGF-R signaling has been recently described, suggesting the existence of a close link between the two pathways which control PCa progression (Bonaccorsi et al. 2004).

The purpose of our study was to determine whether the inhibition of EGF-R signaling pathway could attenuate the metastatic potential of human PCa cells. In particular, we verified if the invasive ability of an in vivo selected bone-seeking PCa cell line demonstrated molecular dependence on EGF-R activation.

\section{Materials and Methods}

\section{Cell culture}

The PC3 human prostate cancer cell line was originally obtained by ATCC (Rockville, MD, USA) and was maintained in DMEM supplemented with $10 \%$ fetal bovine serum, glutamine and penicillin-streptomycin (Sigma). PCb1 and PCb2 cell lines were obtained in our laboratory through serial selection of excised tumors with bone tropism in nude mice and were partially characterized in a previous study (Angelucci et al. 2004). Human stromal cells were isolated from surgical human bone specimens obtained by routine clinical practice with the informed consent of the patients. The medullar side of bone fragments was delicately scraped with a surgical blade and the recovered cellular material was resuspended in $\alpha$-MEM containing antibiotics. Cells were repeatedly washed and filtered to eliminate cell clumps. Stromal cells were cultured in $\alpha$-MEM supplemented with $20 \%$ fetal bovine serum, glutamine and penicillin-streptomycin (Sigma). The cells were quantified, and primary cultures were established at a plating density of $5 \times 10^{5}$ cells/ $\mathrm{cm}^{2}$ in $\alpha$-MEM supplemented with $20 \%$ fetal bovine serum and antibiotics. The medium was changed initially at day 4 and then every other day thereafter until the cultures reached confluence. In order to evaluate cell proliferation, cells were plated at a density of $10^{4}$ cells $/ \mathrm{cm}^{2}$ at various days of culture and were recovered with a solution of trypsin/EDTA, washed twice with ice cold PBS and counted in a Burker slide. uPA was purchased from Chemicon International Inc. (Temecula, CA, USA). Mouse osteoblasts were isolated from calvaria of 7-day old CD1 mice. Bone were 
cleaned free from soft tissues, and digested three times with $1 \mathrm{mg} / \mathrm{ml}$ Chlostridium histolyticum type IV collagenase and $0.25 \%$ trypsin, for $20 \mathrm{~min}$ at $37^{\circ} \mathrm{C}$, with gentle agitation. Cells from the second and third digestion were plated and grown to confluence in DMEM plus $10 \%$ FBS. At confluence, cells were trypsinized by standard procedure and plated according to the experimental protocol. These cells expressed the osteoblast markers ALP, Runx-2, PTH/PTHrP receptor, type I collagen and osteocalcin.

\section{Fluorescence analysis by FACS}

Quantification of membrane-associated proteins was performed by flow cytometric analysis (FACScan; Becton-Dickinson, Mountain View, CA, USA). Cells were trypsinized, centrifuged, and left at $37^{\circ} \mathrm{C}$ for $1 \mathrm{~h}$ in DMEM $/ 10 \%$ FCS in polypropylene tubes in order to reconstitute cellular external membrane. Cells were washed in saline buffer, fixed for $10 \mathrm{~min}$ at $4{ }^{\circ} \mathrm{C}$ with a $4 \%$ buffered formalin solution, washed, and resuspended at $1 \times 10^{6}$ cells $/ \mathrm{ml}$. Pellets were incubated with $1 \mu \mathrm{g} / \mathrm{ml}$ primary antibody at $4{ }^{\circ} \mathrm{C}$ for $1 \mathrm{~h}$. Then, cells were washed twice and incubated with FITCconjugated anti-mouse secondary antibody at $4{ }^{\circ} \mathrm{C}$ for $1 \mathrm{~h}$. Finally, after two more washes, cells were resuspended in $1 \mathrm{ml}$ of phosphate buffer (PBS) and analyzed by flow cytometer. All the flow cytometric measurements were done under the same instrument settings, and at least 5000 cells were measured for each sample. Expression levels were evaluated as fluorescence index in the presence of the relevant antibody and reported as the ratio between this value and background staining of cells incubated with fluorescent secondary antibody only.

\section{Animals and experimental in vivo models}

Male CD1 nude mice (Charles River, Milan, Italy) were maintained under the guidelines established by our Institution (University of L'Aquila, Medical School and Science and Technology School Board Regulations, complying with the Italian government regulation n.116, January 271992 for the use of laboratory animals). Before any invasive manipulation, mice were anesthesized with a mixture of ketamine $(25 \mathrm{mg} / \mathrm{ml}) /$ xylazine $(5 \mathrm{mg} / \mathrm{ml})$. Xenografts were obtained by injecting s.c. $1 \times 10^{6}$ tumor cells in $100 \mu 1$ of $12 \mathrm{mg} / \mathrm{ml}$ Matrigel (Becton Dickinson, Franklin Lakes, NJ, USA). Tumor growth was monitored daily by measuring the average tumor diameter (two perpendicular axes of the tumor were measured by a caliper). The volume of the tumor was expressed in $\mathrm{mm}^{3}$ according to the formula $4 / 3 \pi r^{3}$. After 20 days, mice were sacrificed by carbon dioxide inhalation and tumor mass was excised and weighed.

Heart injection of PCa cells was performed as previously described (Angelucci et al. 2004). Briefly, a 27 gauge needle on a tuberculin syringe containing $1 \times 10^{5}$ tumor cells in $0.1 \mathrm{ml}$ of PBS was inserted in the second left intercostal space of four-week old nude mice. Animals were sacrificed by carbon dioxide inhalation 40 days after heart injections, or earlier if there were early signs of serious distress. The development of metastases was monitored weekly by radiography using a Faxitron cabinet x-ray system (Faxitron x-ray corp., Wheeling, IL, USA). Burden of osteolytic lesions was evaluated by digital examination of radiography (ImageJ, a public domain software by Wayne Rasband, NIH, USA). All animals were subjected to an accurate necroscopy and portions of various organs were processed for routine histological examination.

\section{Real-time PCR}

Total RNA was extracted from cultured cells using Genelute Mammalian Total RNA kit (Sigma) according to the manufacturer's protocol. To eliminate possible contamination by DNA, RNA samples were treated with 1 unit DNase I (Sigma). RNA was quantified by spectrophotometric analysis and $1 \mu \mathrm{g}$ of RNA was used to synthesize cDNA (SuperScript III Platinum Kit, Invitrogen). Real-time PCR analysis was performed using Stratagene MX3000P personal Q-PCR (M-medical) in the presence of SYBR Green. The PCR reagents were provided in SuperScript III Platinum Kit (Invitrogen), and the conditions were chosen according to manufacturer's protocol. For all genes, $5 \mu \mathrm{l}$ of cDNA were used except for GAPDH amplification which was performed using $2.5 \mu \mathrm{l}$ of cDNA. Primers were designed using the online tool Primer3 (http://frodo.wi.mit.edu/cgi-bin/primer3/ primer3_www.cgi) and the sequences were as follows: EGF-R forward primer: 5'-TAATCTGTGTGTGCCCTGTA-3', reverse primer 5'-TTCCTTGATAAATTGGATGG-3'; HER2 forward primer: 5'GGAGTCTTTGTGGATTCTGA-3', reverse primer: 5'-GGTCGCTTTTGTTCTTAGAC-3'; uPA-R forward primer 5'-GCCTTACCGAGGTTGTGTGT-3', reverse primer $5^{\prime}$-CATCCAGGCACTGTTCTTCA-3' uPA forward primer: 5'-TGGTCTTTCTGGAGAGGTTA-3', reverse primer: 5'-CAGTGAGGATTGGATGAACT 3'; GAPDH forward primer: 5'GGCCTCCAAGGAGTAAGACC- $3^{\prime}$, reverse primer: 5'-AGGGGTCTACATGGCAACTG-3'; RANKL forward primer: 5'-CCTTTTGCTCATCTCACTATT-3', 
reverse primer: 5'-AATGTTGGCATACAGGTAATA-3'; OPG forward primer: 5'-TGCTGTTCCTACAAAGTTTACG-3', reverse primer: $5^{\prime}$ CTTTGAGTGCTTTAGTGCGTG-3'. Mean threshold cycle $(\mathrm{Ct})$ values were determined by Stratagene software using three distinct amplification curves for each gene. Relative expression of the target gene was estimated using the formula: relative expression $=2^{-\Delta \mathrm{Ct}}$, were $\Delta \mathrm{Ct}=\mathrm{Ct}$ (target gene) $-\mathrm{Ct}$ (GAPDH). The relative gene expressions are not comparable among different genes because the $\mathrm{Ct}$ (target gene) was multiplied by different factors.

\section{Alu-PCR analysis}

Alu elements are short repetitive sequences present only in the primate genome, reaching a copy number of over a million per genome. In order to detect human Alu, mice were sacrificed by carbon dioxide inhalation and the rear limbs were immediately processed. Bones were accurately deprived of surrounding soft tissues and opened with a surgical blade in order to expose the medulla. Bone fragments were incubated with $100 \mathrm{mM}$ Tris- $\mathrm{HCl}$ pH 8.5, 0.5 M EDTA, 10\% SDS, $5 \mathrm{M} \mathrm{NaCl}$, $20 \mathrm{mg} / \mathrm{ml}$ proteinase $\mathrm{K}$ at $37^{\circ} \mathrm{C}$ for $12 \mathrm{~h}$. DNA was isolated by phenol/chloroform extraction, precipitated with ethanol and suspended in $0.1 \mathrm{M}$ Tris- $-\mathrm{HCl} \mathrm{pH} 8.0$, 0.5 M EDTA. After spectrophotometric quantification, DNA was subjected to 30 cycles of PCR amplification for Alu elements using the primers 5'-CGAGGCGGGTGGATCATGAGGT- $3^{\prime}$ and 5'-TCTGTCGCCCAGGCCGGACT-3'(Roy-Engel et al. 2001) and the amplified sequence was visualized by $2 \%$ agarose gel electrophoresis.

\section{Invasion assays}

PVPF $8 \mu \mathrm{m}$ polycarbonate filters (Nucleopore, Concorezzo, Milan, Italy) were coated on one side with $250 \mu \mathrm{g} / \mathrm{ml}$ Matrigel, rinsed once with PBS and then placed in contact with the lower chamber containing chemoattractants. Cells $\left(1 \times 10^{5}\right.$ per chamber $)$ were trypsinized, washed twice with PBS, rinsed in complete medium and incubated at $37^{\circ} \mathrm{C}$ for $30 \mathrm{~min}$ to reconstitute the membrane structures and then added to the upper compartment of each chamber in medium without FCS. Cells were allowed to migrate through coated filters for $8 \mathrm{~h}$. The cells attached on the lower membrane surfaces were stained with $0.1 \%$ crystal violet in $0.1 \mathrm{M}$ borate, $\mathrm{pH} 9.0$ and $2 \%$ ethanol for $20 \mathrm{~min}$ at room temperature. Cells were counted at $\times 400$ magnification in standard optical microscopy and the average number of cells per field in five random fields was recorded. Triplicate filters were used and the experiments were repeated three times.

\section{Western blotting and immunoprecipitation}

Total cell lysates were obtained resuspending the cells in buffer containing $1 \%$ Triton, $0,1 \%$ SDS, $2 \mathrm{mM}$ $\mathrm{CaCl}_{2}, 100 \mu \mathrm{g} / \mathrm{ml}$ phenylmethyl sulfonyl fluoride. Protein content was determined using the Protein Assay Kit 2 (Bio-Rad Laboratory, Hercules, CA, USA). $40 \mu \mathrm{g}$ of proteins were electrophoresed in $10 \%$ SDS-polyacrylamide gel and then electrotransferred to nitrocellulose membrane (Schleicher \& Schuell, Dassel, Germany), which was then blocked overnight with $10 \mathrm{mM}$ Tris- $\mathrm{HCl}$, pH 8.0, $150 \mathrm{mM} \mathrm{NaCl}, 0.05 \%$ Tween-20 (TBS-T) containing 10\% non-fat dry milk. The membrane was then incubated with $1 \mu \mathrm{g} / \mathrm{ml}$ of polyclonal anti-EGF, anti-p-EGF-R (Tyr 1173), uPA (H140) or MMP-9 (2C3) (Santa Cruz Biotechnology, Santa Cruz, CA, USA) primary antibodies in TBS-T and with specific horseradish peroxidaseconjugated secondary antibodies in TBS-T. Protein bands were visualized using a chemiluminescent detection system (Amersham Biosciences, Piscataway, NJ, USA). For EGF-R immunoprecipitation, lysates with the same amount of protein in the same volume were incubated overnight at $48^{\circ} \mathrm{C}$ with anti-EGF-R antibody, and protein-G-Sepharose beads (Calbiochem, San Diego, CA, USA) were then added for a further $2 \mathrm{~h}$. After washing once with the cold lysis buffer and four-times with ice-cold PBS, the immunoprecipitates were then processed for detecting co-immunoprecipitated EGFR as described in this section.

\section{Protease expression by zymography}

Expression and activation of gelatinase B (proMMP-9) was analyzed by zymography performed using an SDS-polyacrylamide gel copolymerized with $0.1 \mathrm{mg} / \mathrm{ml}$ gelatine. For plasminogen activator analysis, gels were made by copolymerizing SDS-polyacrylamide with $0.1 \mathrm{mg} / \mathrm{ml}$ lactose-free casein and $15 \mathrm{mg} / \mathrm{ml}$ human plasminogen. Gels were washed three times with $50 \mathrm{mM}$ Tris- $\mathrm{HCl}(\mathrm{pH} 7.4)$ containing $2 \%$ Triton $\mathrm{X}-100$ for $15 \mathrm{~min}$ under shaking conditions to remove SDS. Then gels were incubated in Tris- $\mathrm{HCl}(\mathrm{pH} 7.4)$ containing $10 \mathrm{mM} \mathrm{CaCl}_{2}, 200 \mathrm{mM} \mathrm{NaCl}$ (for gelatinases), or without salts (for plaminogen activators) at $37^{\circ} \mathrm{C}$. At the end of incubation, gels were fixed and stained with $0.1 \%$ Coomassie Blue solution. Enzymedigested regions were identified as white bands against a blue background. 
a

\begin{tabular}{ccc} 
& \multicolumn{2}{c}{ Metastases } \\
\cline { 2 - 3 } & Bone & Other sites \\
\hline PC3 & $7 / 10$ & $3 / 10$ \\
\hline PCb1 & $7 / 10$ & $2 / 10$ \\
\hline PCb2 & $9 / 10$ & $2 / 10$ \\
\hline
\end{tabular}

b

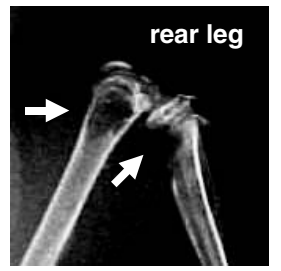

C
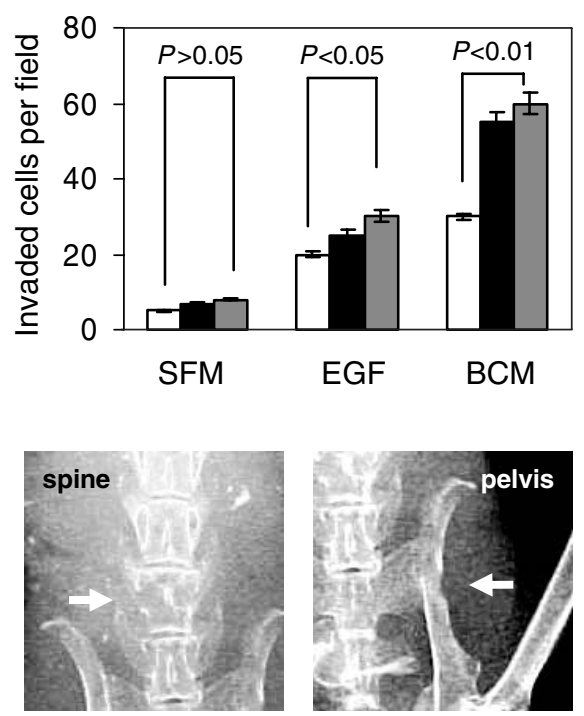

Figure 1 Metastatic ability of PC3 cell sub-lines. (a) Number of mice with metastases 40 days after intracardiac injection of the same amount $\left(1 \times 10^{5}\right)$ of PCa cells. (b) Representative radiographies of nude mice injected with $1 \times 10^{5} \mathrm{PCb} 2$ cells showing preferential sites of bone mestastases. Arrows indicate the osteolytic lesions derived from metastatic tumor activity. (c) The invasive ability of PC3 sub-lines are compared with parental cells in the presence of serum free medium (SFM), of $50 \mathrm{ng} / \mathrm{ml}$ EGF, and of bone stromal cell conditioned medium (BCM). The results are the mean of five independent experiments.

The test was performed allowing cells to migrate across Matrigel for $8 \mathrm{~h}$.

\section{Statistical analysis}

Results are expressed as means \pm s.D. for at least three distinct experiments. Demonstration of significant differences among means were performed by Student's $t$ analysis considering 0.05 the threshold value of $P$. Differences in the success rate between treatments in vivo were compared with $\chi^{2}$ test for $2 \times 2$ tables. All statistical analyses were performed using Kaleidagraph 3.6 (Synergy Software, Reading, PA, USA).

\section{Results}

\section{Selection of highly metastatic PC3 cell sub-lines}

The injection of PC3 cells in the left ventricle of nude mice recapitulates the natural spreading of tumor cells through arterial circulation, leading to metastasis formation. In our model, the injection of $1 \times 10^{5}$ PC3 cells produced bone metastases in $70 \%$ of mice (Fig. 1a). Non-bone metastases were less frequent and involved primarily lungs and lymph-nodes. Bone metastases were induced starting from the third week after cell injection and reached a variable burden, causing after 5 weeks, the complete destruction of cortical bone in about $20 \%$ of mice. One tumor mass excised from bone metastasis with extracortical growth was used to establish a new cell line termed PCb1. $\mathrm{PCb} 2$ cell line was obtained from a bone metastasis generated by $\mathrm{PCb} 1$ cells as previously described (Angelucci et al. 2004). In order to test their metastatic ability, the two PC3 cell sub-lines were injected in the heart with the same procedure used for PC3 cells. Results indicated that only $\mathrm{PCb} 2$ cells were able to form bone metastases in a greater percentage of mice compared to PC3 cells (Fig. 1a). Although PCb1 cells generated the same number of bone metastases as PC3 cells, we noticed that the bone osteolytic lesions were more uniformly distributed in the entire skeleton in comparison to parental cells that colonized preferentially at the rear leg. Bone metastases were visible as lytic lesions by X-ray scan and were localized primarily in the epiphysis of tibias and femurs (Fig. 1b). Other less common sites of lytic lesions were omerus, spine, and pelvis (Fig. 1b). PCb1 and PCb2 cells showed the same growth rate both in standard culture conditions and in vivo when injected s.c. (data not shown). The invasive potential of sub-lines was tested in vitro within the fifth cell culture passage. When cells were seeded for $8 \mathrm{~h}$ on Matrigel-coated filters, in absence of chemotactic gradient or serum, less than 10 cells were able to cross the Matrigel barrier without any significant difference among the three cells lines. Both in the presence of EGF and of bone stromal cell 
a

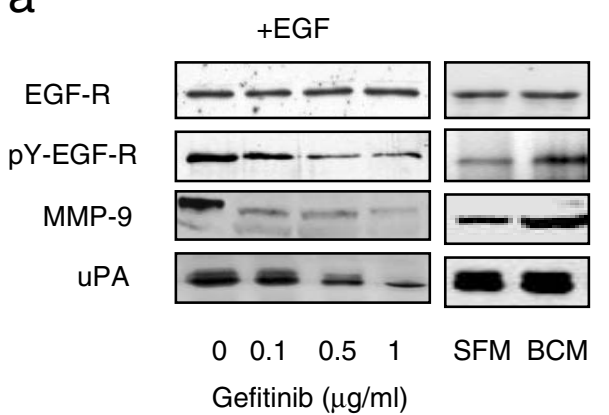

b

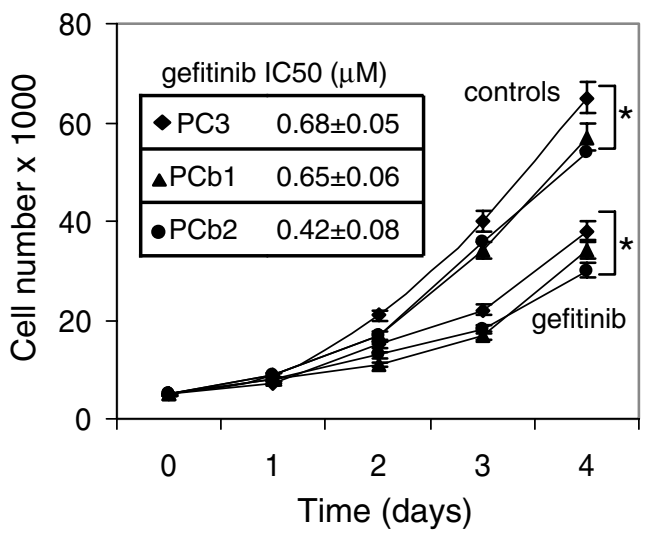

C

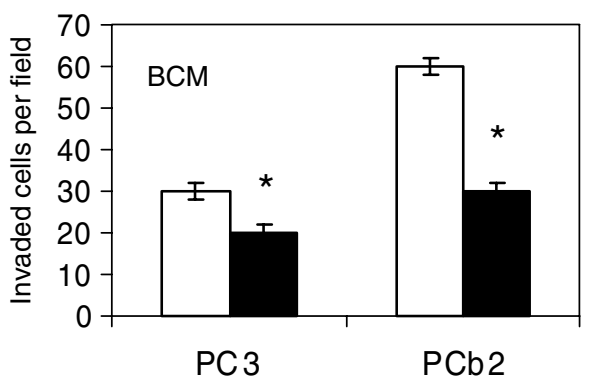

d

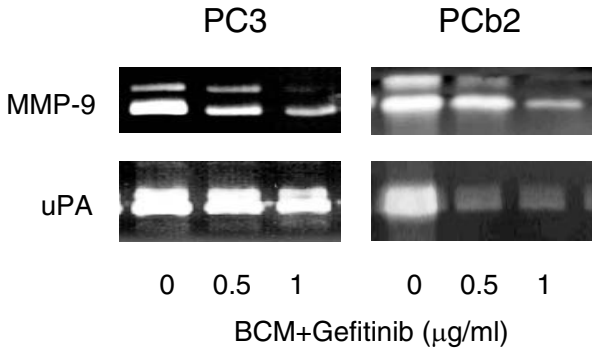

Figure 2 Effect of gefitinib on PCa cells. (a) Relative levels of total and auto-phosphorylated EGF-R, MMP-9 and uPA in presence of three different concentrations of gefitinib $(0.1,0.5,1 \mu \mathrm{M})$, serum-free medium (SFM), bone stromal cell conditioned medium (BCM). (b) Growth curves of PCa cells cultured in presence of $50 \mathrm{ng} / \mathrm{ml}$ EGF (control) or of $50 \mathrm{ng} / \mathrm{ml}$ EGF plus $60 \mu \mathrm{g} / \mathrm{ml} \mathrm{gefitinib}$. The concentration of gefitinib was chosen calculating the mean of the three different IC50 (table, inset). The results are the mean of three independent experiments. ${ }^{*} P(\mathrm{PC} 3$ vs PCb1) and $P(\mathrm{PC} 3$ vs PCb2) $>0.1$ (c) $0.5 \mu \mathrm{g} / \mathrm{ml}$ gefitinib (black columns) was added to PC3 and PCb2 cells 30 min before the invasion test and during the experiment. Invasion assay was performed allowing cells to migrate across a Matrigel coated filter. Cells were counted after $8 \mathrm{~h}$ and the chemoattractant used was BCM. The results are the mean of five independent experiments. ${ }^{*} P<0.01$. (d) MMP-9 and uPA activity by zymography in PC3 and $\mathrm{PCb} 2$ conditioned media recovered after $48 \mathrm{~h}$ of incubation in the presence of BCM and two concentrations of gefitinib (0.5 and $1 \mu \mathrm{M})$.

conditioned medium (BCM), we observed an increase of about 4-fold in invaded PC 3 cells in comparison to basal conditions. $\mathrm{PCb} 1$ and $\mathrm{PCb} 2$ cells showed a progressive increase in their invasive ability in the presence of EGF and BCM. The difference when compared to PC3 cells was particularly evident in the presence of BCM. As shown in Fig. 1c about $50 \%$ more of $\mathrm{PCb} 2$ cells were invaded, compared to $\mathrm{PC} 3$ cells and were counted in the opposite surface of Matrigel-coated filters.

\section{The effect of gefitinib on in vitro PCa cell proliferation and invasion}

The addition of different doses of gefitinib in the range of $0.1-1 \mu \mathrm{M}$ inhibited, in a dose dependent manner, the EGF-R autophosphorylation in PC3 cells compared with total EGF-R (Fig. 2a). Cells were treated with gefitinib in the presence of $50 \mathrm{ng} / \mathrm{ml}$ EGF in serum-free medium (SFM) and the blockade of EGF-R activation was observed within $30 \mathrm{~min}$. An increment in the presence of the phosphorylated form of EGF-R, but not in its total form, was observed not only in the presence of EGF but also when cells were cultured in SFM plus $30 \%$ of BCM (Fig. 2a). The effect was observed $24 \mathrm{~h}$ after the cell starvation and within $4 \mathrm{~h}$ after the addition of BCM. When we analyzed the presence of proteolytic enzymes in conditioned medium of PC3 after $24 \mathrm{~h}$ of treatment with EGF or $\mathrm{BCM}$, we observed an increment in the secreted metalloprotease-9 (MMP-9) and uPA. The presence of increasing doses of gefitinib was able to markedly reduce the presence of MMP-9 and UPA in conditioned medium (Fig. 2a). 

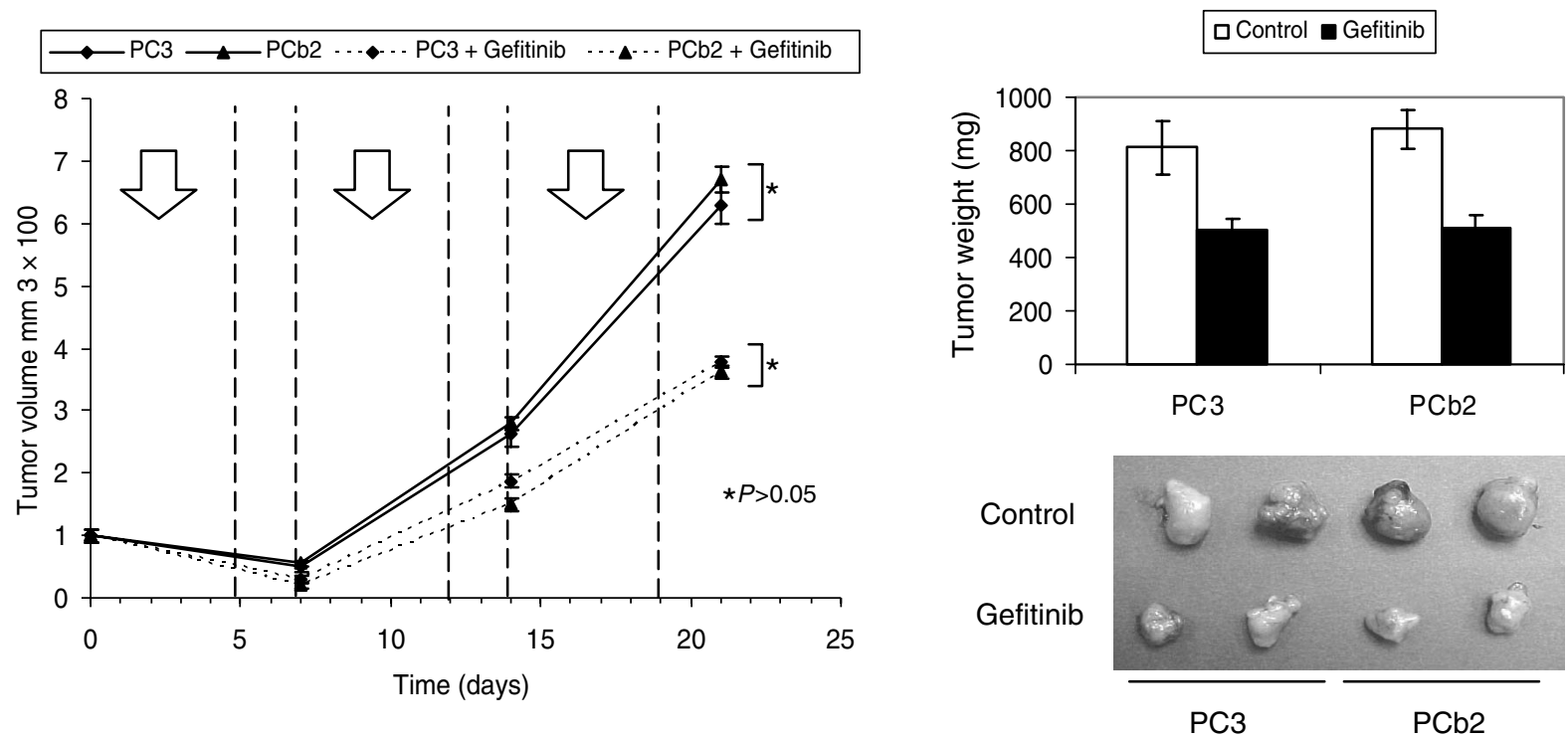

Figure 3 Inhibition of xenograft growth by gefitinib. (a) Mice were inoculated s.c. with PC3 or PCb2 cells and were divided in two groups: one received oral administration of drug vehicle, and the other received $150 \mathrm{mg} / \mathrm{kg}$ of gefitinib. The drug and the vehicle alone were given in the days indicated by white arrows. Tumor volume was measured at days 7,14 and 21 . The results are the mean of three independent experiments. ${ }^{\star} P>0.05$. (b) At the 21 st day animals were sacrificed and tumors were excised and weighed. Histograms show the mean reduction in tumor mass weight. Photos of four representative tumors for each cell line in control and in treated groups are shown.

PCa cells showed a significant reduction in their proliferative capacity $72 \mathrm{~h}$ after the treatment with $0.5 \mu \mathrm{M}$ gefitinib, reaching $50 \%$ inhibition after $96 \mathrm{~h}$ (Fig. 2b). The gefitinib did not generate appreciable differences in the proliferative response among different $\mathrm{PCa}$ cell lines as demonstrated also by the $\mathrm{IC}_{50}$ analysis (Fig. 2b, table inset).

In order to test the effect of gefitinib on the invasion of PCa cells, we pre-treated PC3 and PCb2 cells with gefitinib for $1 \mathrm{~h}$ before the invasion assay and added gefitinib in the upper compartment of the Boyden chambers. In Figure $2 \mathrm{c}$ we show the inhibition of $\mathrm{BCM}$-mediated invasion by $0.5 \mu \mathrm{M}$ gefitinib. In order to evaluate if the pro-invasive effect of $\mathrm{BCM}$ was dependent on the functionality of EGF-R, we pretreated PCa cells with $0.5 \mu \mathrm{M}$ gefitinib and then seeded cells in the presence of BSM in a Boyden chamber. Both PC3 and PCb2 cells matched with gefitinib showed a reduced ability to degrade and invade Matrigel in the presence of BCM, but while the inhibition in PC3 cells was about $30 \%$ compared to control. In PCb2 cells, we observed a more evident effect generating a reduction of about $50 \%$ in invaded cells relative to control. When we evaluated the proteolytic activity in conditioned media from PC3 and $\mathrm{PCb} 2$ cells treated with gefitinib for $24 \mathrm{~h}$ we observed a decrease in both gelatinolytic and caseinolytic activity, with the higher effect observed for uPA secretion by PCb2 cells.

\section{Gefitinib inhibition of the in vivo $\mathrm{PCa}$ cell proliferation}

In order to generate tumor xenografts, $\mathrm{PC} 3$ and $\mathrm{PCb} 2$ cells were injected s.c. with Matrigel in nude mice. Tumor volume was monitored weekly and the results were expressed as mean values. When we injected an equal number of $\mathrm{PC} 3$ and $\mathrm{PCb} 2$ cells, the growth rates of cell lines were very similar (Fig. 3a). Mice did not show any sign of distress until the end point, and necroscopy did not reveal the presence of metastases. Ten mice per cell line were randomly selected among twenty and each underwent treatment with $150 \mathrm{mg} / \mathrm{kg}$ gefitinib for 4 cycles of 5 consecutive days, separated by 2 days without drug administration. Control groups received the vehicle according the same schedule (Fig. 3a). After three cycles of treatment, at day 21 we sacrificed the animals and measured tumor volume and weight. Groups treated with gefitinib revealed a significant reduction in tumor volume appreciable 
Table 1 Inhibitory effect of gefitinib on metastasis formation

\begin{tabular}{|c|c|c|c|c|c|}
\hline \multirow[b]{2}{*}{ Treatement group } & \multirow[b]{2}{*}{ Body weight (g) } & \multicolumn{2}{|c|}{ Metastases ( $n /$ total number of mice) } & \multicolumn{2}{|c|}{ Metastases (\% reduction) } \\
\hline & & Bone $(\%)$ & Other sites (\%) & Bone & Other sites \\
\hline PC3 & 20 & $12 / 16(75)$ & $4 / 16(25)$ & - & - \\
\hline PC3 + gefitinib & 17 & $8 / 20(40)$ & $2 / 20(10)$ & $47 \%(a)$ & $60 \%$ \\
\hline $\mathrm{PCb} 2$ & 20 & 16/18 (89) & $3 / 18(17)$ & - & - \\
\hline $\mathrm{PCb} 2+$ gefitinib & 18 & $3 / 18(17)$ & $1 / 18(6)$ & $81 \%(b)$ & $65 \%$ \\
\hline
\end{tabular}

(a) $P=0.037$; (b) $P<0.001$. Mice were inoculated by heart injection with PC3 or PCb2 cells and were divided in two groups: one received oral administration of drug vehicle, and the other received $150 \mathrm{mg} / \mathrm{kg}$ of gefitinib. The drug and the vehicle alone were given in 4 cycles of 5 days with two days without drug, starting from the second day after tumor cell injection. Privileged sites of metastasis other than bone were lung and abdominal lymph nodes. Number of metastases and their reduction in presence of gefitinib are indicated.

from day 10 and reaching an end point value of $50 \%$ compared to the untreated groups. However, the response of $\mathrm{PC} 3$ and $\mathrm{PCb} 2$ cells to gefitinib did not differ and the mean volume of tumors treated with the drugs were very similar along the entire experiment. The same result was obtained measuring tumor weight (Fig. 3b). In the bottom panel of figure 3b, we show representative images of two tumors excised from each experimental group.

\section{Reduction of experimental bone metastasis by gefitinib}

Next we evaluated the effectiveness of gefitinib in metastatic blockade by using the heart injection experimental model. Mice were divided in four groups according to the type of cell line inoculated (PC3 or $\mathrm{PCb} 2$ ) and of the treatment (drug vehicle or $150 \mathrm{mg} / \mathrm{kg}$ gefitinib). Mice receiving gefitinib did not show any additional signs of distress compared to the control group, except for a statistically not significant reduction in the median body weight. At the end point, 5 weeks after cardiac injection, the overall number of metastases by PC 3 cells in the gefitinib treated group was about half of the control group. In fact, bone metastases were visible by radiography only in $8 / 20$ mice, while necroscopic analysis revealed the presence of metastatic foci in non-bone sites only in $2 / 20$ mice vs $4 / 16$ of the control group (Table 1). As expected, PCb2 cells were able to generate a higher number of bone metastases compared to PC3 cells. Mice with at least one evidence of bone lesion were about the $90 \%$ of total inoculated mice. The treatment with gefitinib demonstrated to be very effective in the reduction of bone metastases generated by $\mathrm{PCb} 2$ cells, which developed in less than $20 \%$ of the mice (Table 1). Although PC3 and its sub-lines caused severe osteolytic metastases in vivo, their conditioned medium or co-culture had no effect on maturation of mouse osteoclasts from precursor cells in vitro (data not shown) (Inoue et al. 2005). In order to address the role of osteoblasts in the gefitinib induced reduction of lytic lesions, we performed primary culture from mouse bone marrow and evaluated the mRNA expression levels of the receptor activator of Nf-kappa-B ligand (RANKL, osteoclastogenesis inducer) and osteoprotegerin (OPG, osteoclastogenesis repressor) in osteoblasts (Fig. 4a). Mouse osteoblasts were treated with gefitinib or with conditioned medium of PC3 and PCb2 cells cultured with or without gefitinib. Conditioned media from $\mathrm{PCa}$ cells determined a strong upregulation in RANKL mRNA, particularly in PCb2 cells. Gefitinib determined a significant reduction in the capacity of $\mathrm{PCa}$ conditioned medium to induce the expression of RANKL, while the direct treatment of osteoblasts did not induce any significant change in RANKL levels. Expression levels in OPG mRNA were always lower in basal conditions but the different treatments failed to show significant differences. Since all mice bearing bone metastases showed lytic lesions in rear limbs, we planned to verify the presence of PCa cells in femur and tibia also by a more sensitive method. Bone medulla of control and treated animals were recovered and analysed for the presence of human Alu sequence by PCR amplification and gel electrophoresis. The same procedure, performed using serial dilution of PC3 cells injected directly in mouse bone medulla, demonstrated that the technique allowed us to reveal as little as 1000 human cells (data not shown). Alu analysis showed the presence in bone medulla of PC 3 cells in about $85 \%$ and of PCb2 cells in more than $90 \%$ of control mice, with an increment of $15 \%$ and $5 \%$, respectively in positive mice compared with the $\mathrm{X}$ ray analysis (Fig. 4b). By carrying out digital analysis of X-ray films, we measured the extension of the lytic lesions present in the corresponding legs. It was 
a

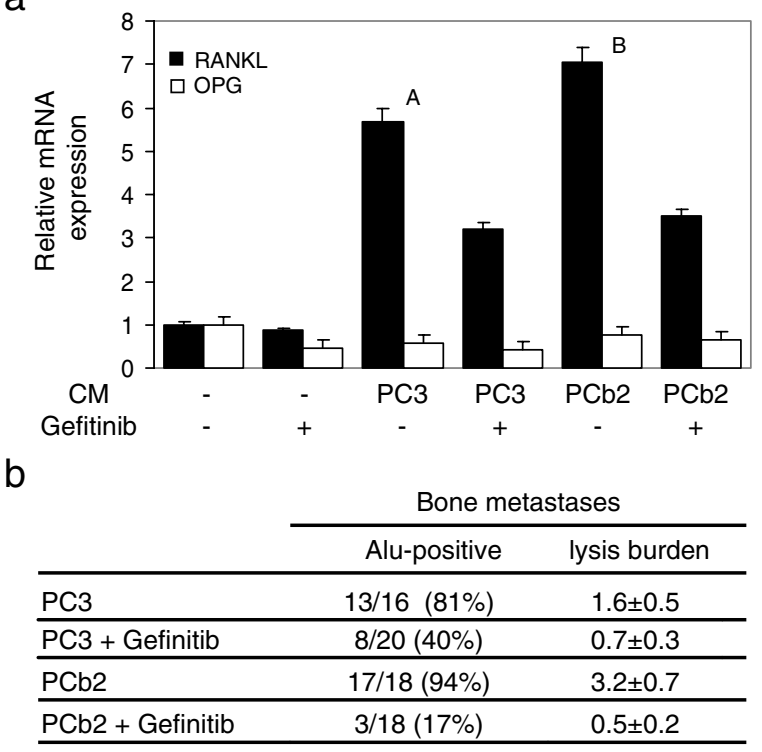

C

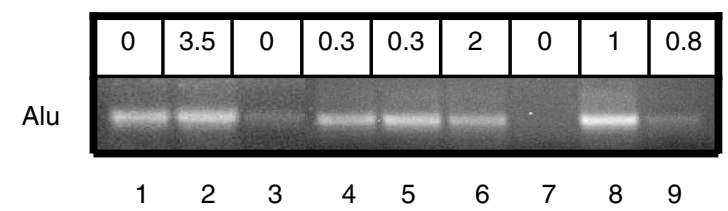

Figure 4 Comparative analysis of bone metastasis formation between control and in gefitinib treated mice. (a) RANKL and OPG relative mRNA expression levels in mouse osteoblasts by quantitative-PCR. Osteoblasts were incubated with conditioned medium (CM) from PC3 and PCb2 cells cultured for $48 \mathrm{~h}$ with or without $0.5 \mu \mathrm{M}$ gefitinib. $P(\mathrm{~A}$ vs $\mathrm{B})<0.05$. (b) Number of Alu-positive mice and mean extension ( \pm s.D.) of lytic lesions in rear limbs for each group of treatment. Radiographs of tibia and femur were analyzed by software elaboration in order to measure the extension of lytic lesions expressed in $\mathrm{mm}^{2}$.

(c) Representative results from 9 different limbs of PCb2 cell injected mice. In the presence of lytic lesions both in tibia and femur the total burden was summed. The same bones were subjected to DNA extraction from bone medulla. DNA from adjacent tibia and femur were pooled and subjected to PCR analysis for the presence of the Alu sequences.

observed that gefitinib was also effective in the reduction of lytic burden. This phenomenon was particularly evident in $\mathrm{PCb} 2$ injected mice because they usually developed larger lytic lesions than PC3 injected ones (Fig. 4b). In Fig. 4c we show a comparative analysis between representative results obtained by X-ray and Alu-PCR analysis of PCb2 generated metastases. While all $\mathrm{X}$-ray positive mice resulted also positive for the presence of $\mathrm{PCb} 2$ cells, two X-ray negative mice showed detectable levels of Alu-sequences (lane 1 and 3, Fig. 4c).

\section{Molecular characterization}

In order to explain the differential response of $\mathrm{PCb} 2$ cells to gefitinib relative to parental cells, we investigated the expression level of key molecular determinants involved in EGF-R activation. First, we performed a relative quantification of mRNA expression by real-time PCR using primers specific for EGFR, HER2, uPAR and uPA (Table 2). EGF-R mRNA was detected at the same level in all PCa cell lines while HER2 mRNA was significantly less expressed in $\mathrm{PCb} 2$ cells compared to parental cells. On the contrary, we observed a significant increment in both uPAR and uPA expression in PCb2 cells compared to PC3 cells. PCb1 cells showed an intermediate phenotype expressing more uPA-R, but not uPA mRNA compared to PC3 cells. In order to confirm these results, we analyzed this expression also at the protein level. In particular we examined the presence on the plasma membrane of EGF-R, HER2, UPA-R and uPA by cytofluorimetric analysis (Fig. 5). Data obtained by real-time PCR were substantially confirmed with a significant increase in uPA-R and uPA expression as shown in the representative experiment (Fig. 5a, lower panel). As indicated by statistical analysis, PCb2 cells expressed significantly less EGF-R and HER2 than PC3 cells. In order to evaluate a possible interaction between UPA-R and EGF-R, we first verified the capacity of exogenous uPA to activate EGF-R. PC3 cells were starved for $24 \mathrm{~h}$ and cell lysates were extracted after a short incubation (30 min) with uPA in serum-free medium (SFM). The addition of $50 \mu \mathrm{g} / \mathrm{ml}$ uPA determined a strong activation of EGF-R when compared with SFM. Then we immunoprecipitated EGF-R and examined the expression levels of p-EGFR and UPA-R. PCa cells were treated with BCM for $4 \mathrm{~h}$ prior to protein extraction. In PCb2 cells, a higher amount of uPA interacted with EGF-R compared to $\mathrm{PC} 3$ cells. Moreover, the complex observed in PCb2 contained mainly EGF-R in the active form.

\section{Discussion}

The progression of PCa implies that the acquisition of several new invasion abilities by cancer cells according to modalities and timing, are not easily predicted by clinical investigation. For this reason, it is very difficult to individualize an effective therapeutic approach, enabling the complete eradication of a tumor that has progressed to an advanced stage. Moreover, experimental models based on commercial cell lines fail in many cases to resemble the fundamental clinical characteristics of tumors. One of the most challenging 
Table 2 Relative gene expression at the level of mRNA by quantitative-PCR analysis in PC3 cell line and its sub-lines

\begin{tabular}{lccrrr}
\hline & \multicolumn{3}{c}{ Relative expression (s.D.) } & & \multicolumn{1}{c}{$\boldsymbol{P}$-values } \\
\cline { 2 - 5 } Gene & PC3 & PCb1 & PCb2 & (a) & (b) \\
\hline EGF-R & $3.52(0.24)$ & $3.23(0.32)$ & $2.80(0.25)$ & 0.57 & 0.08 \\
HER2 & $1.81(0.13)$ & $1.84(0.21)$ & $1.43(0.18)$ & 0.83 & $<.03$ \\
uPA-R & $2.51(0.65)$ & $4.52(0.71)$ & $11.92(0.83)$ & $<01$ & $<0.01$ \\
UPA & $0.63(0.04)$ & $0.82(0.05)$ & $2.03(0.02)$ & 0.01 \\
\hline
\end{tabular}

(a) PC3 vs PCb1; (b) PC3 vs PCb2.

a

\begin{tabular}{ccccc} 
& \multicolumn{2}{c}{ Fluorescence Index (S.D.) } & \\
\cline { 2 - 4 } Protein & PC3 & PCb1 & PCb2 & $P(\#)$ \\
\hline EGF-R & $2.4(0.9)$ & $2.2(0.6)$ & $1.8(0.6)$ & 0.01 \\
HER2 & $1.5(0.5)$ & $1.7(0.8)$ & $1.0(0.5)$ & 0.05 \\
UPA-R & $1.7(0.7)$ & $3.5(0.8)$ & $7.0(1.5)$ & $<0.01$ \\
UPA & $2.1(0.5)$ & $2.5(0.5)$ & $5.7(0.9)$ & $<0.01$
\end{tabular}

$\#=\mathrm{PC} 3$ vs $\mathrm{PCb} 2$

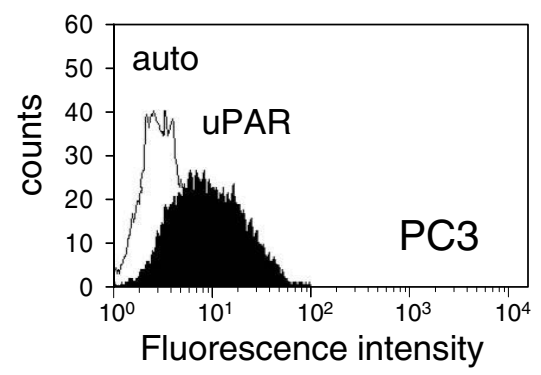

b

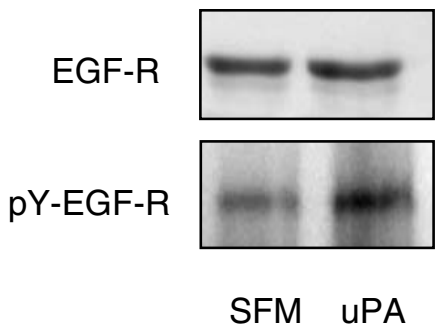

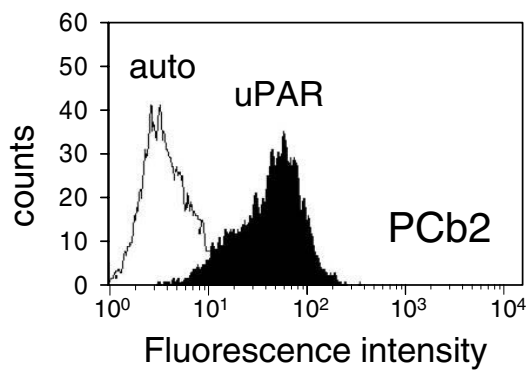

C

IP: anti EGF-R

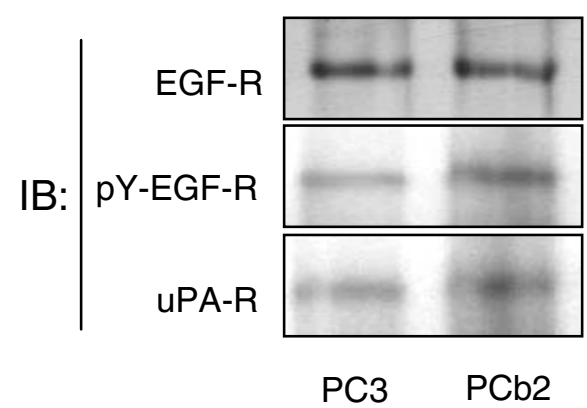

Figure 5 EGFR and uPAR in PC3 cell line and its sub-lines. (a) Expression on the cellular surface by cytofluorimetric analysis. The fluorescence index, calculated as described in Methods and materials, represents the mean of three different analyses. Fluorescence patterns obtained in PC3 and PCb2 cells using anti-uPA-R antibody are shown in the lower panel. White peak represents the auto-fluorescence (auto) observed when cells were treated only with the secondary antibody. (b) Relative levels of total and auto-phosphorylated EGF-R in presence of serum-free medium (SFM) and SFM plus $50 \mathrm{ng} / \mathrm{ml}$ uPA. (c) PC3 and $\mathrm{PCb} 2$ cells were treated for $4 \mathrm{~h}$ with $\mathrm{BCM}$. EGFR was immunoprecipitated (IP) and the immune complex analyzed by immunoblot (IB) for EGFR total mass, phosphorylated EGFR and uPAR. 
difficulties in tumor progression modelling is represented by the generation of an adequate pattern of metastases. The reasons are several, including an inadequate molecular asset acquired by tumor cells through their in vitro culturing. Once injected in mice these cells frequently fail to form visible tumors in short time, often entering into a phase of dormancy (Aguirre-Ghiso et al. 2003). Our experience has demonstrated that the highly aggressive potential of the PC3 cell line was easily overcome by sub-lines selected by their ability to colonize bone. The propensity of PC3 cells to form lytic lesions especially in rear limbs demonstrated that anatomical features also represent an important co-factor in the bone colonizing ability of tumor cells (Yoneda 1997). However this characteristic was partially lost by the first derived sub-line PCb1, that was able to metastasize in several different bone sites, demonstrating a more 'pure' molecular bone tropism. We hypothesized that PC3 sub-lines, during the acquisition of increased metastatic potential might be selected for the expression of specific molecular determinants that are already present in the parental cell line.

The PC3 cell line was originally derived from a bone metastasis and since it lacks the expression of the androgen receptor, it represents the prototype of hormone-insensitive PCas of poor prognosis. The discovery of new molecular targets controlling different proliferative cellular pathways from AR signaling, may offer new hopes for the rational design of an effective therapy for this kind of PCa. The activation of EGF-R triggers a complex network of downstream cellular pathways, modulating different cellular responses including apoptosis, angiogenesis, adhesion and motility. In effect, EGF-R inhibitors, including gefitinib, were able, as described by our research group and by other authors, to reduce the growth of PCa cells both in vivo and in vitro. As demonstrated by xenograft experiments, the highly selective metastatic sub-line PCb2 did not show any significant difference in its in vivo proliferative capacity in response to gefitinib compared to the original PC3 cell line. On the contrary, we observed that $\mathrm{PCb} 2$ cells were particularly responsive to gefitinib in their invasive and metastatic ability. The acquisition of a new dependence on EGF-R in $\mathrm{PCb} 2$ cells was gained in absence of an upregulation of EGF-R or HER2 expression. The analysis of HER2 was performed because the overexpression of EGF-R-homologous HER2 receptor, which is highly expressed in several human cancers, can potentiate EGF-R function by: increasing EGF binding affinity, stabilizing and recycling EGF-RHER2 heterodimers; expanding the repertoire of receptor-associated substrates and signaling responses (Karunagaran et al. 1995, Worthylake et al. 1999). Although our data show that HER2 expression is not appreciably modulated in highly metastatic PCa cells, suggesting that HER2 over-expression is not a driven event during the acquisition of bone tropism. We can not exclude that targeting HER2 may be useful in determining a further reduction in the number of metastases. We hypothesized that the gain of function observed in $\mathrm{PCb} 2$ cells was mainly due to the expression of key molecular determinants other than EGF-R and was able to direct its activation to different functions. Increasing evidence suggests that many of the cellular responses triggered by EGF-R are not only activated by EGF or TGF- $\alpha$, but also by association with intracellular signal transduction factors or membrane associated proteins. The interaction with specific components probably determines the nature of the downstream cellular effects generated by EGF-R activation. One emerging candidate in modulating the response through EGF-R activation is uPA-R. The assembly of a multimeric complex formed by $\mathrm{UPA}$, uPA-R, integrins and EGF-R is a predictor of in vivo behaviour of different carcinomas including PCa (Aguirre-Ghiso et al. 2003). In our work we demonstrated that exogenous uPA was able to induce EGF-R autophosphorylation in the absence of known EGF-R ligands. The transactivation of EGF-R by uPA-R was already shown in breast cancer, where interestingly it appears to mediate cellular invasiveness rather than proliferation (Guerrero et al. 2004). In addition, as we previously demonstrated using the same experimental model, the inhibition of uPA-R expression, through the administration of antisense oligo anti-uPAR, significantly influences the production of bone metastases by PC3 cells (Margheri et al. 2005). The activation of EGF-R by uPA may be facilitated by the formation of complexes containing uPA-R. These complexes in the highly metastatic cell line $\mathrm{PCb} 2$ are more abundant and facilitate the activation of EGF-R. Since gefitinib was able to preferentially block metastatic dissemination, the association between EGF-R and $\mathrm{UPA}-\mathrm{R}$ seems to represent an important determinant in a specific phase of disease progression. In particular, the functional interactions between these two receptors raise the possibility that extensive influence in bone homing and remodelling may occur in PCa cells. Several factors playing a key role in normal bone remodelling have been described to also determine the predilection of $\mathrm{PCa}$ cells for the bone microenvironment, namely EGF, TGF- $\alpha$ and uPA (Daci et al. 1999, Cooper et al. 2003). The finding that bone is a potential storehouse 
of growth factors and that PCa cells in culture respond to bone-derived growth factors, suggests that the release of these factors during metastatic bone remodelling may induce a positive feedback mechanism in tumor growth. PC3 cell line and its sub-lines failed to induce in vitro osteoclastogenesis. On the contrary, the activation of osteoclasts and the subsequent induction of bone resorption induced by tumor cells are thought to depend on the balance of the local RANKL-OPG ratio determined by osteoblasts activity. Both PC3 and the highly metastatic PCb2 cell lines are able, through the release of soluble factors, to induce a strong overexpression in RANKL mRNA in mouse osteoblasts. So our data suggest that the action of gefitinib in the bone microenvironment depends on a dual mechanism: direct inhibition of tumor cell proliferation and blockade in the cross-talk between tumor and bone cells. Recent work by Normanno et al. (2005) demonstrated that gefitinib may play a role in osteoclastogenesis inhibiting EGF-R present in continuous stromal-like cell lines. This mechanism could also be important in our experimental model, although our data indicates that gefitinib acts mainly through the modulation of factors released by tumor cells. Among these factors, which need further investigation, may also include EGF-R ligands secreted by PCa cells. However, we did not observe any direct effect of gefitinib on mouse osteoblasts in vitro.

The analysis of Alu sequences in metastatic sites allowed us to determine the presence of silent micrometastases that do not influence bone remodelling, since it is not visible by radiography. Our results showed the concomitant absence of tumor cells and of osteolytic lesions in gefitinib-treated mice, again demonstrating the dual role of EGF-R inhibition. We thus hypothesized that gefitinib blocked bone tropism of PCa cells in a very early phase of metastatic colonization, preventing the gain of a critical tumor mass in the target organ. The presence of a limiting number of tumor cells was due to a blockade in the establishment of the necessary crosstalk between tumor and bone cells. This could be supported by the establishment of a positive feedback mechanism based on reinforcing an interaction between EGF-R and uPA-R. It has been demonstrated that the expression of UPA and UPAR in PCa cells is a necessary condition for determining the invasive ability downstream from EGF-R signaling (Mamoune et al. 2004, Festuccia et al. 2005a), indicating the existence of a possible additive mechanisms regulating $\mathrm{PCa}$ progression. In particular, the modulation of uPA secretion and activation may play a key role for determining the ability of tumor cells to 'seed' in the bone tissue. Moreover the importance of proteases in the initial stages of tumor implantation in the bone is linked, in addition to the migratory capacity, to the tumor potential in remodelling the bone matrix (Nemeth et al. 2002).

In conclusion, our study demonstrates that the EGF-R tyrosin-kinase inhibitor, gefitinib, is an effective drug in the treatment of the metastastic stages of $\mathrm{PCa}$. Although the specific mechanism of action is not completely understood, gefitinib appears to target the different aspects of the complex molecular processes responsible for bone homing. In particular, our results suggest that even metastatic tumor cell lines retain in vivo a degree of dependence on surface receptors like EGF-R and uPA-R. This observation provides new therapeutic opportunities in controlling the spread of a tumor. This characteristic indicates that gefitinib may be suitable for the clinical control of the early microdissemination of $\mathrm{PCa}$ tumor cells.

\section{Acknowledgements}

We thank the BIOT'AQ consortium (University of L'Aquilla, Italy for the financial and logistic support and Dr Demetrio Del Monaco (AstraZeneca, Milan, Italy)) for his technical assistance.

\section{Funding}

This study was partially supported by a research grant issued to M B by AstraZeneca, Italy. The authors declare that there is no conflict of interest that would prejudice the partiality of this scientific work.

\section{References}

Aguirre-Ghiso JA, Estrada Y, Liu D \& Ossowski L 2003 ERK (MAPK) activity as a determinant of tumor growth and dormancy; regulation by 38 (SAPK). Cancer Research 63 1684-1695.

Angelucci A, Gravina GL, Rucci N, Festuccia C, Muzi P, Vicentini C, Teti A \& Bologna M 2004 Evaluation of metastatic potential in prostate carcinoma: an in vivo model. International Journal of Oncology 25 1713-1720.

Bonaccorsi L, Muratori M, Carloni V, Marchiani S, Formigli L, Forti G \& Baldi E 2004 The androgen receptor associates with the epidermal growth factor receptor in androgen-sensitive prostate cancer cells. Steroids 69 549-552.

Cohen MH, Williams GA, Sridhara R, Chen G, McGuinn WD, Jr., Morse D, Abraham S, Rahman A, Liang C, Lostritto R et al. 2004 United States Food and Drug Administration Drug Approval summary: gefitinib 
(ZD1839; Iressa) tablets. Clinical Cancer Research 10 1212-1218.

Cooper CR, Chay CH, Gendernalik JD, Lee HL, Bhatia J, Taichman RS, McCauley LK, Keller ET \& Pienta KJ 2003 Stromal factors involved in prostate carcinoma metastasis to bone. Cancer 97 739-747.

Daci E, Udagawa N, Martin TJ, Bouillon R \& Carmeliet G 1999 The role of the plasminogen system in bone resorption in vitro. Journal of Bone Mineral Research 14 946-952.

Di Lorenzo G, Tortora G, D'Armiento FP, De Rosa G, Staibano S, Autorino R, D'Armiento M, De Laurentiis M, De Placido S, Catalano G et al. 2002 Expression of epidermal growth factor receptor correlates with disease relapse and progression to androgen-independence in human prostate cancer. Clinical Cancer Research $\mathbf{8}$ 3438-3444.

Festuccia C, Angelucci A, Gravina GL, Biordi L, Millimaggi D, Muzi P, Vicentini C \& Bologna M 2005a Epidermal growth factor modulates prostate cancer cell invasiveness regulating urokinase-type plasminogen activator activity. EGF-receptor inhibition may prevent tumor cell dissemination. Thrombosis and Haemostasis 93 964-975.

Festuccia C, Gravina GL, Angelucci A, Millimaggi D, Muzi P, Vicentini C \& Bologna M 2005b Additive antitumor effects of the epidermal growth factor receptor tyrosine kinase inhibitor, gefitinib (Iressa), and the nonsteroidal antiandrogen, bicalutamide (Casodex), in prostate cancer cells in vitro. International Journal of Cancer 115 630-640.

Frey MR, Golovin A \& Polk DB 2004 Epidermal growth factor-stimulated intestinal epithelial cell migration requires Src family kinase-dependent p38 MAPK signaling. Journal of Biological Chemistry 279 44513-44521.

Guerrero J, Santibanez JF, Gonzalez A \& Martinez J 2004 EGF receptor transactivation by urokinase receptor stimulus through a mechanism involving Src and matrix metalloproteinases. Experimental Cell Research 292 201-208.

Guise TA \& Mundy GR 1998 Cancer and bone. Endocrinology Reviews 19 18-54.

Heiss MM, Allgayer H, Gruetzner KU, Funke I, Babic R, Jauch KW \& Schildberg FW 1995 Individual development and uPA-receptor expression of disseminated tumour cells in bone marrow: a reference to early systemic disease in solid cancer. Nature Medicine 1 1035-1039.

Hernes E, Fossa SD, Berner A, Otnes B \& Nesland JM 2004 Expression of the epidermal growth factor receptor family in prostate carcinoma before and during androgenindependence. British Journal of Cancer 90 449-454.

Inoue H, Nishimura K, Oka D, Nakai Y, Shiba M, Tokizane T, Arai Y, Nakayama M, Shimizu K, Takaha N et al. 2005 Prostate cancer mediates osteoclastogenesis through two different pathways. Cancer Letters 223 $121-128$
Jo M, Thomas KS, O’Donnell DM \& Gonias SL 2003 Epidermal growth factor receptor-dependent and -independent cell-signaling pathways originating from the urokinase receptor. Journal of Biological Chemistry 278 1642-1646.

Jorissen RN, Walker F, Pouliot N, Garrett TP, Ward CW \& Burgess AW 2003 Epidermal growth factor receptor: mechanisms of activation and signaling. Experimental Cell Research 284 31-53.

Karunagaran D, Tzahar E, Liu N, Wen D \& Yarden Y 1995 Neu differentiation factor inhibits EGF binding. A model for trans-regulation within the ErbB family of receptor tyrosine kinases. Journal of Biological Chemistry $\mathbf{2 7 0}$ 9982-9990.

Kim SJ, Uehara H, Karashima T, Shepherd DL, Killion JJ \& Fidler IJ 2003 Blockade of epidermal growth factor receptor signaling in tumor cells and tumor-associated endothelial cells for therapy of androgen-independent human prostate cancer growing in the bone of nude mice. Clinical Cancer Research 9 1200-1210.

Kondapaka SB, Fridman R \& Reddy KB 1997 Epidermal growth factor and amphiregulin up-regulate matrix metalloproteinase-9 (MMP-9) in human breast cancer cells. International Journal of Cancer 70 722-726.

Madarame J, Higashiyama S, Kiyota H, Madachi A, Toki F, Shimomura T, Tani N, Oishi Y \& Matsuura N 2003 Transactivation of epidermal growth factor receptor after heparin-binding epidermal growth factor-like growth factor shedding in the migration of prostate cancer cells promoted by bombesin. Prostate 57 187-195.

Mamoune A, Kassis J, Kharait S, Kloeker S, Manos E, Jones DA \& Wells A 2004 DU145 human prostate carcinoma invasiveness is modulated by urokinase receptor (UPAR) downstream of epidermal growth factor receptor (EGFR) signaling. Experimental Cell Research 299 91-100.

Margheri F, D'Alessio S, Serrati S, Pucci M, Annunziato F, Cosmi L, Liotta F, Angeli R, Angelucci A, Gravina GL et al. 2005 Effects of blocking urokinase receptor signaling by antisense oligonucleotides in a mouse model of experimental prostate cancer bone metastases. Gene Therapy 12 702-714.

Moro L, Venturino M, Bozzo C, Silengo L, Altruda F, Beguinot L, Tarone G \& Defilippi P 1998 Integrins induce activation of EGF receptor: role in MAP kinase induction and adhesion-dependent cell survival. EMBO Journal 17 6622-6632.

Nemeth JA, Yousif R, Herzog M, Che M, Upadhyay J, Shekarriz B, Bhagat S, Mullins C, Fridman R \& Cher ML 2002 Matrix metalloproteinase activity, bone matrix turnover, and tumor cell proliferation in prostate cancer bone metastasis. Journal of the National Cancer Institute 94 17-25.

Normanno N, De Luca A, Aldinucci D, Maiello MR, Mancino M, D'Antonio A, De Filippi R \& Pinto A 2005 gefitinib inhibits the ability of human bone marrow stromal cells to induce osteoclast 
differentiation: implications for the pathogenesis and treatment of bone metastasis. Endocrine-Related Cancer 12 471-482.

Rabbani SA, Rajwans N, Achbarou A, Murthy KK \& Goltzman D 1994 Isolation and characterization of multiple isoforms of the rat urokinase receptor in osteoblasts. FEBS Letters 338 69-74.

Rabbani SA, Harakidas P, Davidson DJ, Henkin J \& Mazar AP 1995 Prevention of prostate-cancer metastasis in vivo by a novel synthetic inhibitor of urokinase-type plasminogen activator (uPA). International Journal of Cancer 63 840-845.

Roy-Engel AM, Carroll ML, Vogel E, Garber RK, Nguyen SV, Salem AH, Batzer MA \& Deininger PL 2001 Alu insertion polymorphisms for the study of human genomic diversity. Genetics 159 279-290.

Shi Y, Brands FH, Chatterjee S, Feng AC, Groshen S, Schewe J, Lieskovsky G \& Cote RJ 2001 Her-2/neu expression in prostate cancer: high level of expression associated with exposure to hormone therapy and androgen independent disease. Journal of Urology 166 1514-1519.

Sirotnak FM, She Y, Lee F, Chen J \& Scher HI 2002 Studies with CWR22 xenografts in nude mice suggest that ZD1839 may have a role in the treatment of both androgen-dependent and androgen-independent human prostate cancer. Clinical Cancer Research 8 3870-3876.

Small EJ \& Vogelzang NJ 1997 Second-line hormonal therapy for advanced prostate cancer: a shifting paradigm. Journal of Clinical Oncology 15 382-388.

Vicentini C, Festuccia C, Gravina GL, Angelucci A, Marronaro A \& Bologna M 2003 Prostate cancer cell proliferation is strongly reduced by the epidermal growth factor receptor tyrosine kinase inhibitor ZD1839 in vitro on human cell lines and primary cultures. Journal of Cancer Research Clinical Oncology 129 165-174.

Wakeling AE, Guy SP, Woodburn JR, Ashton SE, Curry BJ, Barker AJ \& Gibson KH 2002 ZD1839 (Iressa): an orally active inhibitor of epidermal growth factor signaling with potential for cancer therapy. Cancer Research 62 5749-5754.

Worthylake R, Opresko LK \& Wiley HS 1999 ErbB-2 amplification inhibits down-regulation and induces constitutive activation of both ErbB-2 and epidermal growth factor receptors. Journal of Biological Chemistry 274 8865-8874.

Yoneda T 1997 Arterial microvascularization and breast cancer colonization in bone. Histology Histopathology 12 1145-1149.

Zellweger T, Ninck C, Bloch M, Mirlacher M, Koivisto PA, Helin HJ, Mihatsch MJ, Gasser TC \& Bubendorf L 2005 Expression patterns of potential therapeutic targets in prostate cancer. International Journal of Cancer 113 619-628.

Zolfaghari A \& Djakiew D 1996 Inhibition of chemomigration of a human prostatic carcinoma cell (TSU-pr1) line by inhibition of epidermal growth factor receptor function. Prostate 28 232-238.

Zyzak LL, MacDonald LM, Batova A, Forand R, Creek KE \& Pirisi L 1994 Increased levels and constitutive tyrosine phosphorylation of the epidermal growth factor receptor contribute to autonomous growth of human papillomavirus type 16 immortalized human keratinocytes. Cell Growth and Differentiation 5 537-547. 